\title{
POLA BERAT DAGING RAJUNGAN BERDASARKAN BERAT TUBUH YANG TERTANGKAP DI PERAIRAN SELAT MADURA
}

\section{PATTERN OF CRAB MEAT WEIGHT BASED ON BODY WEIGHT CAUGHT IN THE MADURA STRAIT}

\author{
Muhammad Zainuri* \\ Program Studi Ilmu Kelautan, Universitas Trunojoyo Madura, Jalan Raya Telang, Kamal, \\ Bangkalan, Indonenesia 69162 \\ ${ }^{*}$ Corresponding author e-mail: zainborn@rocketmail.com
}

Submitted: 12 Agustus 2016 / Revised: 4 Oktober 2016 / Accepted: 29 Oktober 2016

DOI: http://dx.doi.org/10.21107/jk.v9i2.1565

\begin{abstract}
Information on ratio of meat blue swimming crab weight have both economically and ecological meanings. The aim of this research is to know actual ratio of the weight of meat whereas catches on Madura Strait fishing ground. Samples were taken from October 2012 - December 2013 and May 2014 - November 2014 by long-line and trammel net. The result showed that having tree (3) modes of average ratio of meat blue swimming crab weight which reached highest on May, October and December of year; whereas the percentage of actual the weight of meat (ratio between average of the weight of meat and body weight) appeared on June and September of year. The result of this research also be known that there is tendency slightly increased of percentage of actual meat weight on blue swimming crab's $50 \mathrm{~g}$ of body weight and more.
\end{abstract}

Keywords: Ratio of meat, Body weight, Madura Strait, blue swimming crab

\section{PENDAHULUAN}

Zainuri (2015) menyatakan, bahwa hasil tangkapan rajungan dengan menggunakan alat tangkap Trammelnet dan Pancing Rawai di perairan Selat Madura cenderung lebih banyak yang mempunyai lebar karapas lebih besar dari $10 \mathrm{~cm}$. Selain itu, persentase rajungan jantan yang tertangkap dengan Trammelnet dan Pancing Rawai masingmasing adalah $74,77 \%$ dan $52,48 \%$, sedangkan rajungan betinanya masingmasing adalah $25,23 \%$ dan $47,52 \%$.

Jika merujuk kepada hasil penelitian yang dilakukan oleh Kamaruddin (2014) di perairan bagian selatan Kabupaten Pamekasan (Madura) dengan menggunakan krakat (pukat pantai), maka ukuran rajungan yang tertangkap mempunyai ukuran lebar karapas berkisar antara $5-10 \mathrm{~cm}$ atau berat berkisar antara 42,0 - 98,0g, sedangkan hasil penelitian yang dilakukan oleh Firdianto (2014) dengan menggunakan bubu di perairan Bluto Kabupaten Sumenep (Madura), yaitu berkisar antara 7,3-12,2 dan lebar karapas yang dihasilkan dengan menggunakan trammelnet berkisar antara $5,5-6,8 \mathrm{~cm}$. Hasil tangkapan tersebut, yaitu jenis kelamin dan ukurannya sangat menentukan terhadap nilai jual dari rajungan itu sendiri. Pada tingkatan pemasaran, kenyataan yang ada, bahwa rajungan tidak dibeli dengan indikator lebar karapas tetapi dalam bentuk berat tubuh. Mempertimbangkan, bahwa berat tubuh rajungan bisa bervariasi berdasarkan umur dan berfluktuasi berdasarkan kepada kondisi aktual rajungan pada saat tertangkap, misalnya rajungan yang masih baru mengalami masa pergantian kulit(moulting), maka akan cenderung mempunyai berat tubuh yang lebih ringan dibandingkan dengan rajungan dengan ukuran yang sama tetapi tidak mengalami masa pergantian kulit (moulting). Begitu pula jenis kelamin, selain jenis kelamin mempengaruhi berat daging yang dikandungnya, tetapi kenyataan di pasar, bahwa rajungan bertelur cenderung mempunyai nilai jual yang lebih tinggi dan itu hanya bisa dimiliki oleh rajungan betina. Bagaimana sebenarnya berat daging rajungan jantan dan betina bisa dilihat dari 
ukuran tubuhnya, merupakan suatu pertanyaan yang harus dijawab dengan data yang ada dalam penelitian ini.

Seperti telah diuraikan sebelumnya, bahwa nelayan sebenarnya dalam menangkap rajungan, yang diperlukan hanya bobot rajungan yang tertangkap, bukan ukuran karapasnya. Semakin berat ukuran rajungan semakin tinggi harga rajungan di pasar. Dalam hal ini, nelayan membutuhkan data tentang kapan rajungan mempunyai berat tubuh total yang maksimal agar memperoleh nilai jual yang lebih tinggi. Sementara di sisi lain, konsumen memerlukan data tentang berat daging yang maksimal mengingat konsumen terutama pengusaha rajungan yang biasanya menjual hanya dalam bentuk dagingnya saja dengan harapan rajungan yang dibeli dari nelayan dalam kondisi gemuk, yaitu mempunyai ratio antara berat daging dengan berat tubuh total atau berat daging dengan berat karapas yang lebih tinggi. Informasi data tersebut akan menjadi sangat penting sehingga para pengusaha bisa memperkirakan berapa harga yang harus dibayar kepada nelayan untuk sejumlah berat rajungan yang dibeli dengan mempertimbangkan harga berat daging rajungan berdasarkan harga pasar. Selain itu, manfaat lainnya dari informasi tentang berat daging rajungan adalah untuk tujuan konservasi, berapa ukuran berat daging rajungan yang boleh dipasarkan?

Berdasarkan kepada pertimbangan di atas, maka merasa perlu dilakukan pengkajian terhadap hasil tangkapan rajungan yang dilakukan di perairan Selat Madurasehubungan dengan berat tubuh total, berat daging dan berat karapasnya.

Tujuan dari penelitian ini untuk mengetahui keterkaitan berat daging aktual dari rajungan yang ditangkap di perairan Selat Madura berdasarkan berat total dari tubuhnya

\section{MATERI DAN METODE}

Pengambilan sampel dilakukan dengan metode survei, yaitu mengikuti nelayan yang mengoperasikan alat tangkap rajungan di Selat Madura dengan interval 1 (satu) sampai 2 (dua) minggu sekali dalam satu bulan mulai Oktober 2012 Desember 2013 dan Mei 2014 Nopember 2014. Lokasi pengambilan sampel dilakukan di perairan Socah, sekitar pantai Gresik (dekat PT. Maspion) dan di sekitar Pelabuhan Kamal. Jumlah sampel dari rajungan sebanyak 875 ekor. Berat daging dilakukan penimbangan setelah dikeluarkan dari cangkang dengan catatan insang rajungan tidak dimasukkan ke dalam berat daging. Data dianalisa secara diskriptif kuantitatif.

\section{HASIL DAN PEMBAHASAN}

Memperhatikan Gambar 1, dapat diketahui, bahwa terdapat 3 (tiga) mode untuk berat daging rata-rata yang tertangkap di perairan Selat Madura, yaitu setelah mencapai puncaknya pada bulan Desember, yaitu sekitar 32,7 g maka berat daging rata-rata rajunganmengalami penurunan mulai bulan Januari $(26,6 \mathrm{~g})$ sampai bulan April, yaitu mencapai 16,3g. Memasuki bulan Mei, berat daging rata-rata rajungan mengalami peningkatan, yaitu mencapai $27,0 \mathrm{~g}$ untuk selanjutnya mengalami penurunan sampai mencapai titik terendah pada bulan Agustus, yaitu $11,0 \mathrm{~g}$. Peningkatan secara signifikan terlihat pada bulan September dan mencapai puncaknya pada bulan Oktober, yaitu $31,5 \mathrm{~g}$ dan kemudian hanya sebulan mengalami penurunan, yaitu pada bulan Nopember selanjutnya meningkat lagi pada bulan Desember. Jika diperhatikan dari hasil tersebut, maka periode penurunan berat daging rata-rata pada bulan Nopember tersebut merupakan periode penurunan yang paling singkat dibandingkan dengan periodeperiode penurunan lainnya. Jadi ada 3 (tiga) puncak tingginya berat daging rata-rata yang tertangkap di Selat Madura, yaitu pada bulan Mei, Oktober dan Desember.

Secara umum dapat dikatakan, bahwa semakin tinggi berat tubuh total dari rajungan, maka akan semakin tinggi berat daging yang dikandungnya. Hal tersebut dapat dibuktikan dengan hasil analisa yang disajikan pada Gambar 2 di bawah ini, yaitu grafik hubungan antara berat tubuh total (sumbu X) dan berat daging (sumbu $Y$ ) rajungan. Jadi hasil tangkapan rajungan yang diperoleh dari perairan Selat Madura, bahwa berat tubuh total yang besar sebagai representasi berat karapas dan berat daging cenderung menghasilkan daging yang lebih banyak juga, misalnya untuk rajungan dengan berat tubuh total $50 \mathrm{~g}$, maka identik dengan berat daging $21,8 \mathrm{~g}$ atau untuk rajungan dengan berat tubuh total $150 \mathrm{~g}$, maka identik dengan berat daging $61,5 \mathrm{~g}$. 


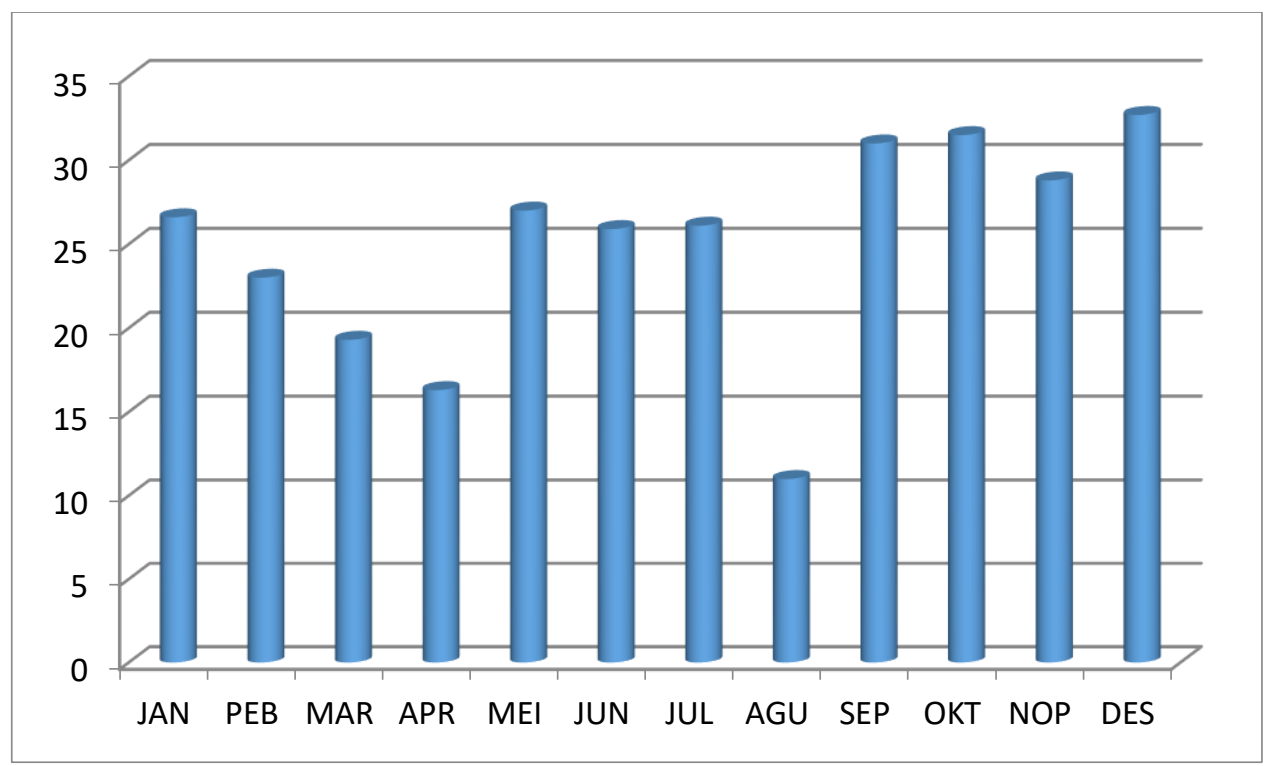

Gambar 1. Berat daging rata-rata Rajungan (gram) selama periode penelitian

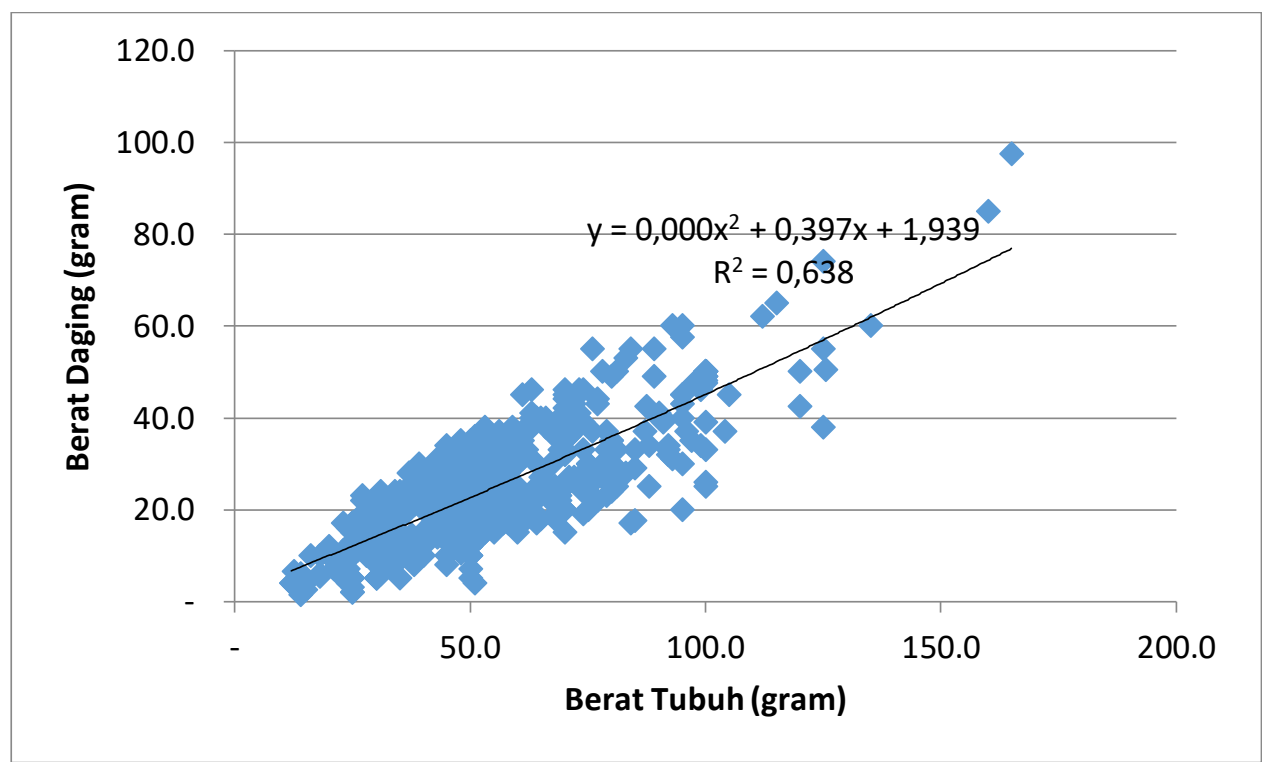

Gambar 2. Grafik hubungan antara berat tubuh total (gram) dengan berat daging Rajungan (gram)

Oleh karena itu, untuk kebutuhan konservasi rajungan, maka sangat penting untuk diperhatikan, bahwa selayaknya nelayan menangkap rajungan yang mempunyai ukuran besar mengingat rajungan yang besar akan menghasilkan daging yang lebih banyak. Bagaimanapun juga harus ada kajian dari pengusaha rajungan berkaitan dengan ukuran rajungan dengan pertimbangan berat dagingnya yang bisa memberikan nilai jual yang lebih tinggi. Jadi pengusaha bisa membuat batasan bahwa ukuran minimal yang bisa dijual ke perusahaan tersebut, sehingga dengan demikian hasil tangkapan nelayan yang tidak akan terbeli bisa dikembalikan lagi ke laut atau dipelihara (budidaya) sampai mencapai ukuran yang akan dibeli oleh perusahaan.

Namun demikian, hasil yang tergambar pada Gambar 1 hanya menunjukkan besarnya jumlah daging yang ada pada seekor rajungan, tetapi belum menunjukkan apakah rajungan yang dibeli oleh pengusaha ataupun konsumen dapat dikatagorikan gemuk atau kurus? Hal ini sangat penting untuk ditunjukkan mengingat konsumen ataupun pengusaha membeli rajungan 
kepada produsen dalam hal ini nelayan, berat yang digunakan adalah berat total, yaitu berat daging ditambah dengan berat karapasnya. Untuk mengetahui seberapa berat daging tersebut mengisi besarnya karapas yang dipunyai oleh seekor rajungan, maka di bawah ini disajikan persentase berat daging rata-rata dari rajungan tersebut.

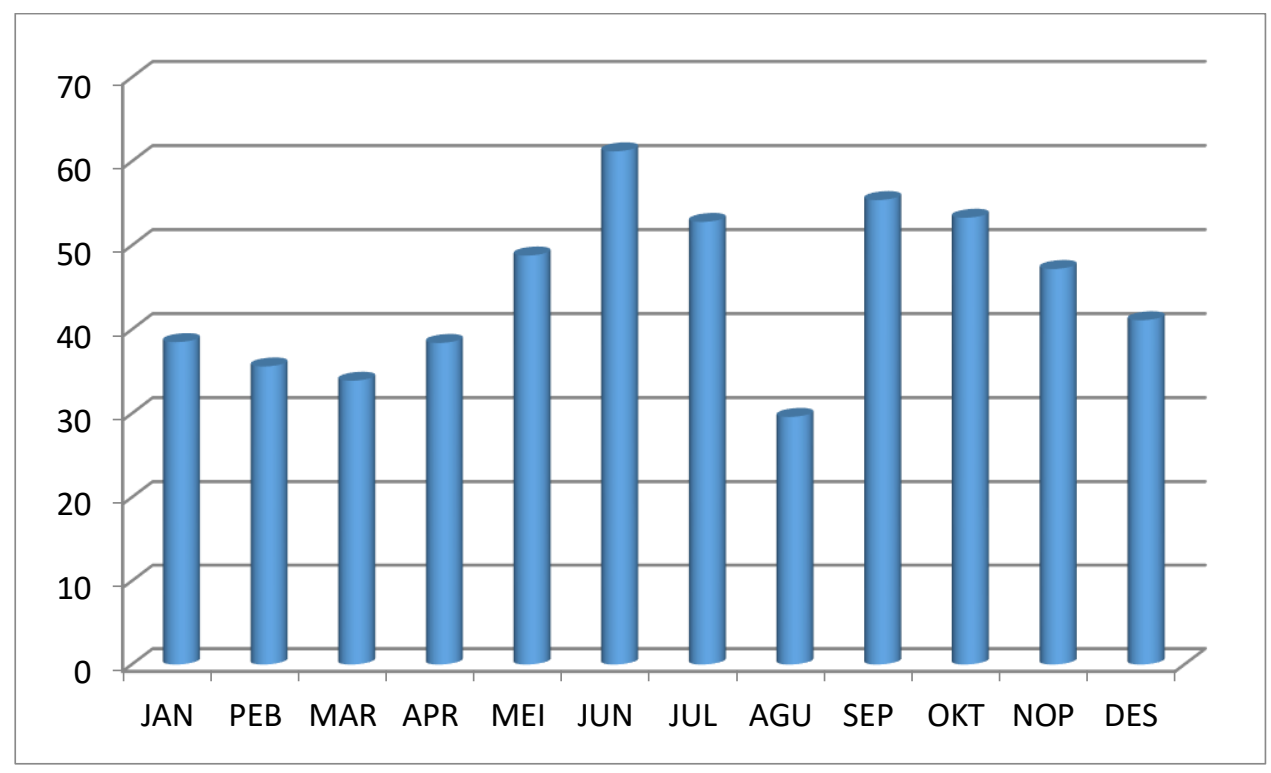

Gambar 3. Persentase berat daging rata-rata

Pada Gambar 3 dapat diketahui, bahwa persentase berat daging rajungan yang tertangkap di Selat Madura berkisar antara $29,6 \%-61,2 \%$ dari berat total rajungan. Persentase berat daging yang dimaksud di sini adalah berat daging rajungan dibandingkan dengan berat total. Persentase berat daging rajungan terendah terjadi pada bulan Agustus dan tertinggi terjadi pada bulan Juni. Hasil ini juga memberikan informasi, bahwa pada bulan Juni dan September kondisi rajungan yang tertangkap lebih gemuk dibandingkan bulan-bulan lainnya. Informasi ini tentunya akan sangat penting terutama bagi pengusaha untuk dapat memperkirakan atau menentukan harga yang layak untuk seekor rajungan pada saat pembelian dari nelayan mengingat pengusaha menjual kembali ke konsumen hanya dalam bentuk dagingnya saja. Sebagai gambaran untuk upaya konservasi, maka diharapkan berat tubuh total minimal yang diperjual belikan di pasar tidak kurang dari $50 \mathrm{~g}$

Sebagai pertimbangan selanjutnya adalah dapat mengetahui bagaimana hubungan antaraberat tubuh total dari rajungan dengan persentase berat daging yang dihasilkannya. Pada Gambar 4 di bawah ini menjelaskan hubungan tersebut. Hasil ini menunjukkan, bahwa persentase daging yang dihasilkan oleh rajungan cenderung mengalami peningkatan seiring dengan pertambahan berat tubuhnya.Berdasarkan hasil penelitian Zainuri (2015), bahwa lebar karapas $10 \mathrm{~cm}$ sebagai batas ukuran lebar karapas rajungan yang boleh ditangkap (Permen KKP-RI No.1 Permen KP/2015) adalah identik dengan sekitar $50 \mathrm{~g}$ untuk berat tubuh. Oleh karena itu, pada Gambar 4 tersebut memperkuat informasi, bahwa ukuran berat tubuh lebih dari $50 \mathrm{~g}$ ternyata mempunyai kecenderungan menghasilkan persentase berat daging yang semakin meningkat, sehingga bisa menjadi dasar bagi pemerintah untuk menetapkan batas ukuran terkecil rajungan yang boleh diperjualbelikan.

Hasil tersebut pada Gambar 4 diperkuat dengan hasil yang diperoleh pada rajungan berkelamin jantan, yaitu sekitar ukuran berat tubuh $50 \mathrm{~g}$ dapat dikatakan sebagai titik awal peningkatan persentase berat daging rajungan (Gambar 5). Pada Gambar 5 tersebut diketahui, bahwa peningkatan persentase berat daging dengan kata lain rajungan mengalami peningkatan kegemukan yang cukup baik setelah mencapai ukuran berat tubuh $50 \mathrm{~g}$ atau lebih. 


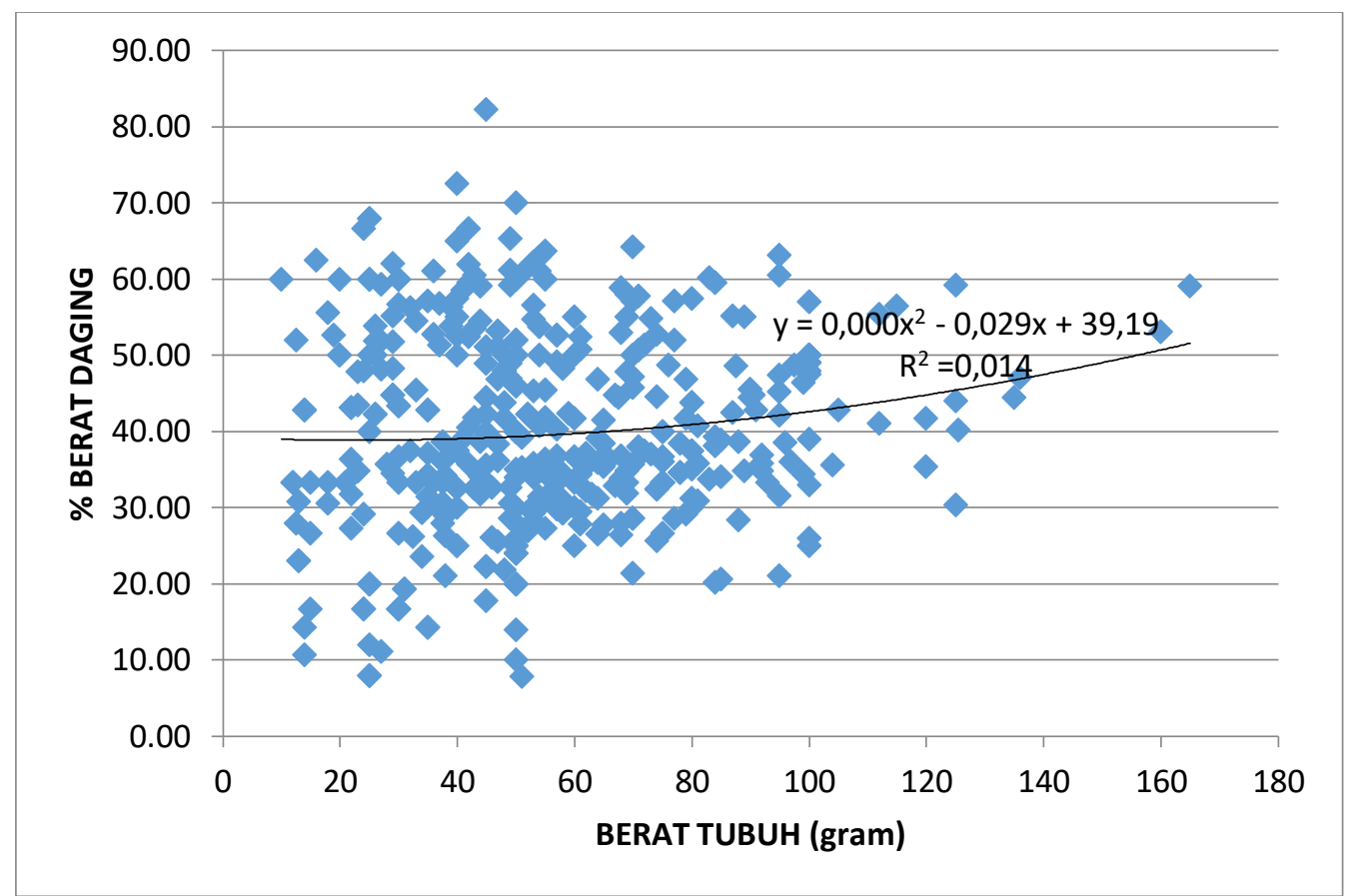

Gambar 4. Keterkaitan Berat Tubuh Rajungan dengan Persentase Berat Daging

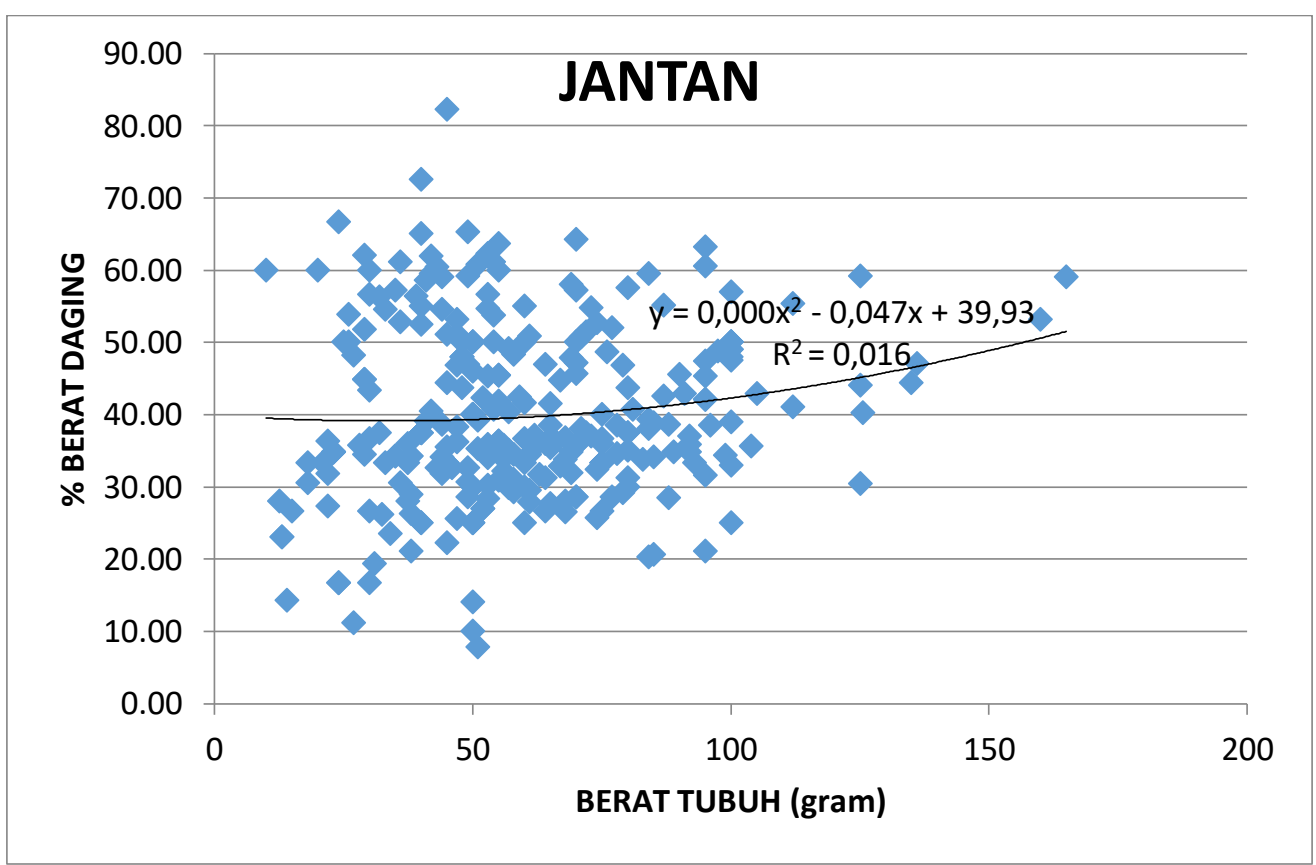

Gambar 5. Keterkaitan Berat Tubuh Rajungan dengan Persentase Berat Daging Untuk Rajungan Berkelamin Jantan

Begitu pula yang terlihat pada hasil analisa terhadap rajungan betina (Gambar 6). Meskipun pada rajungan betina tidak memperlihatkan hasil yang lebih tinggi daripada rajungan jantan, namun kecenderungan yang sama, yaitu semakin tinggi berat tubuh total rajungan, maka ada kecenderungan persentase berat daging yang dihasilkannya akan lebih tinggi juga. 


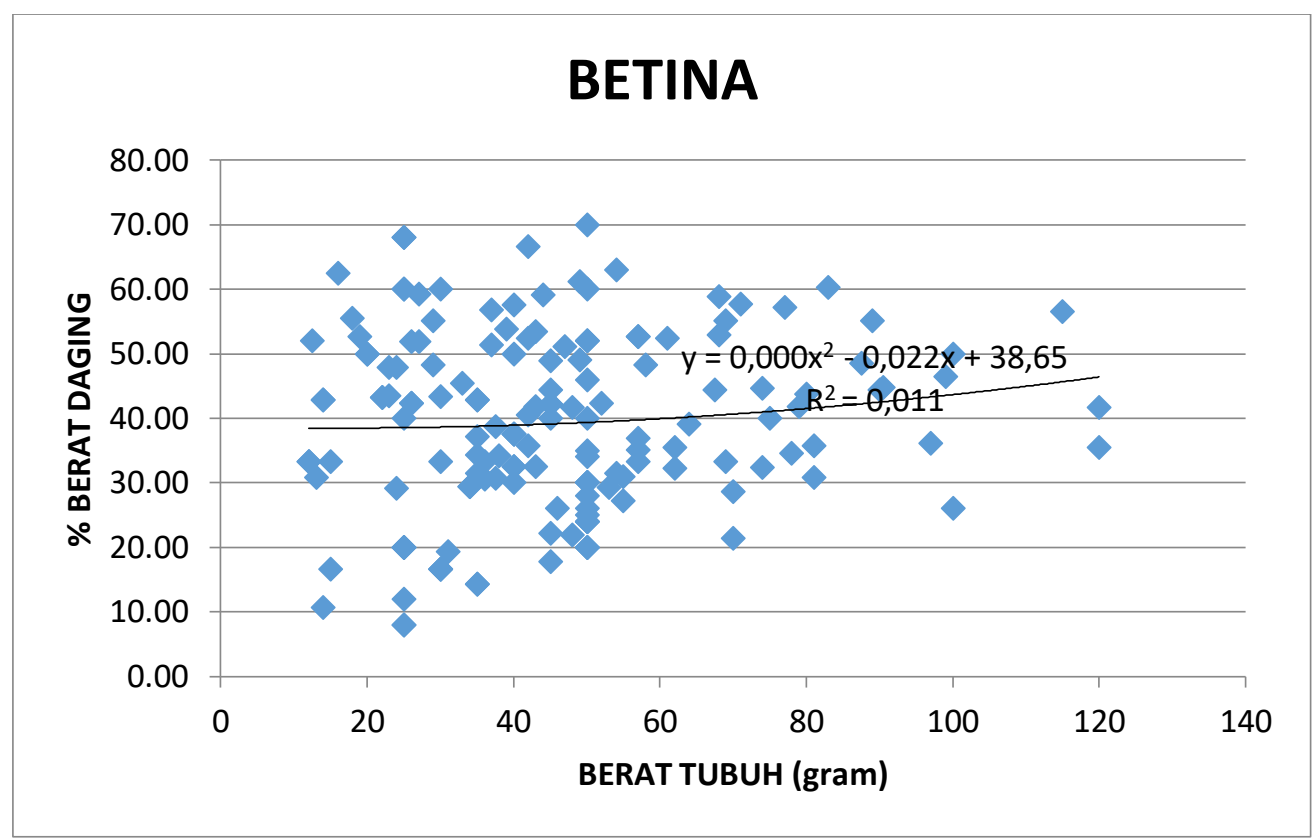

Gambar 6. Keterkaitan Berat Tubuh Rajungan dengan Persentase Berat Daging Untuk Rajungan Berkelamin Betina

Untuk rajungan betina, berdasarkan hasil ini belum memperlihatkan, apakah persentase daging yang dikandungnya oleh seekor rajungan betina berbeda antara yang belum melakukan pemijahan dengan yang sudah melakukan pemijahan? Seberapa besar pengaruh selama proses reproduksi terhadap persentase berat daging rajungan betina? Pertanyaan-pertanyaan tersebut memerlukan jawaban sehingga perlu juga diupayakan untuk diketahui dengan melakukan penelitian lebih lanjut.

\section{KESIMPULAN DAN SARAN}

Rajungan yang tertangkap di perairan Selat Madura diketahui mengalami berat tertinggi dalam siklus tahunan, yaitu pada bulan Mei, Oktober dan Desember. Ada kecenderungan, bahwa semakin tinggi berat tubuh total dari rajungan, maka akan semakin tinggi pula persentase berat daging yang dihasilkannya.

Harapannya, hendaknya hasil ini dapat menjadi acuan bagi user agar kelestarian rajungan masih tetap terjaga

\section{DAFTAR PUSTAKA}

Arios, A. H., Solichin, A. S., \& Saputra, W. (2013). Hasil Tangkapan Rajungan (Portunus pelagicus) dengan Menggunakan Alat Tangkap Bubu Lipat yang Didaratkan di TPI Tanjung
Sari Kabupaten Rembang. Journal of Management of Aquatic Resources, 2(2), 243-248

Chande, A. I., \& Mgaya, Y. D. (2003). The fishery of Portunus pelagicus and species diversity of portunid crabs along the coastal of Dar es Salaam, Tanzania, Western Indian Ocean. J. Mar. Sci. 2(1), 75-84

Firdianto, E. (2015). Studi Hasil Tangkapan Rajungan (Purtunus pelagicus) Dengan Menggunakan Bubu dan Gillnet Pada Substrat Yang Berbeda Di Perairan Pragaan Dan Bluto, Kabupaten Sumenep. (Skripsi). Universitas Trunojoyo Madura. Bangkalan

Hidayat, K. (2015). Studi Hasil Tangkapan Dari Krakat (Beach Seine) Di Pantai Lembung dan Jumiang Kabupaten Pamekasan Berdasarkan Beda Tinggi Air Pada Saat Surut. (Skripsi). Universitas Trunojoyo Madura. Bangkalan

Hosseini, M., Vazirizade, A., Parsa, Y., \& Mansori, A. (2012). Sex ratio, size distribution and seasonal abundance of blue swimming crab, Portunus pelagicus (Linnaeus, 1758) in Persian Gulf coasts, Iran. IDOSI Publications. World Applied Sciences Journal, 17(7), 919-925

Kangas, M. I. (2000). Synopsis of the biology and exploitation of the blue swimmer 
crab, Portunus pelagicus Linnaeus, in Western Australia. Fisheries Research Report 121.

Potter, I. C., \& de Lestang, S. (2000). The biology of the blue swimmer crab Portunus pelagicus in the Leschenault Estuary and Koombana Bay in southwestern Australia. Journal of the Royal Society of Western Australia, 83, 443458
Zainuri, M. (2015). Membaca Peraturan Menteri KKP No. 1/Permen-KP/2015 Mengenai Ukuran Rajungan (Purtunus pelagicus). Prosiding Seminar Nasional Kelautan Universitas Trunojoyo Madura 2015 "Pengelolaan Sumberdaya Kelautan dan Perikanan Wilayah Pesisir dan Pulau-Pulau Kecil Berkelanjutan Menuju Kedaulatan Maritim. $143-147 p$. 